Article

\title{
Colonization with Arbuscular Mycorrhizal Fungi Promotes the Growth of Morus alba L. Seedlings under Greenhouse Conditions
}

\author{
Nan Lu ${ }^{1, \dagger}$, Xia Zhou ${ }^{2, \dagger}$, Ming Cui ${ }^{2, \dagger}$, Meng Yu ${ }^{2}$, Jinxing Zhou ${ }^{1, *}$, Yongsheng Qin ${ }^{3}$ and \\ Yun Li ${ }^{1, *}$
}

1 Beijing Forestry University, Beijing 100083, China; E-Mails: ln_890110@163.com (N.L.); zjx001@bjfu.edu.cn (J.Z.); yunli@bjfu.edu.cn (Y.L.)

2 Institute of Desertification Studies, Chinese Academy of Forestry, Beijing 100091, China; E-Mails: xzhou2013@163.com (X.Z.); cuiming4057@126.com (M.C.); carfeild@163.com (M.Y.)

3 Beijing Municipal Bureau of Landscaping and Forestry, Beijing 100029, China; E-Mail: qinyscn@126.com

$\dagger$ These authors contributed equally to this work.

* Authors to whom correspondence should be addressed; E-Mails: zjx001@bjfu.edu.cn (J.Z.); yunli@bjfu.edu.cn (Y.L.); Tel.: +86-10-62338561 (J.Z.); +86-10-62336094 (Y.L.); Fax: +86-10-62338561 (J.Z.).

Academic Editor: Douglas L. Godbold

Received: 16 October 2014 / Accepted: 25 February 2015 / Published: 16 March 2015

\begin{abstract}
Morus alba L. is an important tree species planted widely in China because of its economic value. In this report, we investigated the influence of two arbuscular mycorrhizal fungal (AMF) species, Glomus mosseae and Glomus intraradices, alone and together, on the growth of $M$. alba L. seedlings under greenhouse conditions. The growth parameters and physiological performance of $M$. alba L. seedlings were evaluated 90 days after colonization with the fungi. The growth and physiological performance of M. alba L. seedlings were significantly affected by the AMF species. The mycorrhizal seedlings were taller, had longer roots, more leaves and a greater biomass than the non-mycorrhizae-treated seedlings. In addition, the AMF species-inoculated seedlings had increased root activity and a higher chlorophyll content compared to non-inoculated seedlings. Furthermore, AMF species colonization increased the phosphorus and nitrogen contents of the seedlings. In addition, simultaneous root colonization by the two AMF species did not improve the growth of
\end{abstract}


M. alba L. seedlings compared with inoculation with either species alone. Based on these results, these AMF species may be applicable to mulberry seedling cultivation.

Keywords: arbuscular mycorrhizal fungi; Glomus species; simultaneous colonization; Morus alba L.

\section{Introduction}

Arbuscular mycorrhizal fungi (AMF) are common endophytic fungi that play an important role in vegetation succession in ecosystems, species productivity and the restoration of damaged ecosystems. About $90 \%$ of the flowering plants, ferns and mosses on Earth have a symbiotic relationship with AMF [1]. Previous studies have demonstrated that AMF may affect multiple metabolic processes in plants and that they promote the evolution, growth, nutritional status, water use, disease resistance and stress resistance of host plants [2,3]. Arbuscular mycorrhizal (AM) symbioses are usually mutualistic and are based on the bidirectional transfer of organic carbon from the plant and soil-derived nutrients, particularly phosphorus $(\mathrm{P})$, nitrogen $(\mathrm{N})$ and zinc, from the fungi [4].

The response of plants to colonization by AMF depends mainly on the host plant and fungal species, as well as on environmental conditions, such as nutrient levels, light intensity and temperature [5]. In previous studies, it has been suggested that plant colonization by different AMF with complementary functions may be more beneficial than colonization with a single species $[6,7]$.

Morus alba L. is native to China and is now widely cultivated (even naturalized) globally. Mulberry leaves are important as the primary food of silkworms, whose cocoon is used to make silk. In addition, mulberry leaves are commonly used in traditional Chinese medicine; for example, $M$. alba L. leaf extracts are used to treat atherosclerosis [8]. Mulberry plants can also help diabetic patients by reducing the absorption of blood glucose. Thus, mulberry has high economic and medicinal value [9].

The application of AMF during the cultivation of mulberry seedlings holds great promise in improving plant nutritional quality, growth and survival under conditions of abiotic stress. To date, only limited reports have explored mulberry inoculation with AMF. Katiyar et al. (1995) demonstrated that vesicular-arbuscular mycorrhizal (VAM) inoculation can help reduce the use of phosphate fertilizer in mulberry cultivation [10]. Mamatha et al. (2002) inoculated ten-year-old mulberry plants with Glomus fasciculatum in field conditions, finding that $\mathrm{P}$ fertilizer application can be reduced by $50 \%$ without reducing yield [11]. However, research regarding the effects of AMF inoculation on the growth of mulberry seedlings is still scarce; and there are no reports on mulberry seedlings simultaneously inoculated with more than one AMF species.

In this report, we investigated the effect of Glomus mosseae and Glomus intraradices on the growth parameters of, photosynthetic pigments of and mineral uptake by mulberry seedlings. To determine whether an AMF community composed of two different species can improve plant growth and mineral uptake more than a single species, a mixture of $G$. mosseae and G. intraradices was also included in our study to increase our understanding of the application of AMF for mulberry seedling cultivation. 


\section{Materials and Methods}

\subsection{Experimental Design}

The substrate used in the pot experiment consisted of turfy soil (Klasmann-Deilmann GmbH, Geeste, Germany), sand and pearl stone mixed at a ratio of 4:3:4. The properties of the substrate were: total N, $3.92 \mathrm{~g} / \mathrm{kg}$; total $\mathrm{P}, 2.147 \mathrm{~g} / \mathrm{kg}$; total potassium $(\mathrm{K}), 43.0 \mathrm{~g} / \mathrm{kg}$; available $\mathrm{N}, 145.85 \mathrm{mg} / \mathrm{kg}$; available $\mathrm{P}$, $55.08 \mathrm{mg} / \mathrm{kg}$; available $\mathrm{K}, 256.1 \mathrm{mg} / \mathrm{kg}$; organic matter, $171.5 \mathrm{~g} / \mathrm{kg}$; and $\mathrm{pH}, 7.23$. The plant growth substrate was sterilized using an autoclave at $0.14 \mathrm{MPa}$ and $121^{\circ} \mathrm{C}$ for $2 \mathrm{~h}$ before use.

Seeds of $M$. alba L. were obtained from the Research Institute of Forestry, Chinese Academy of Forestry. All seeds were surface-sterilized in $10 \%$ hydrogen peroxide $\left(\mathrm{H}_{2} \mathrm{O}_{2}\right)$ for $10 \mathrm{~min}$ and then washed with sterile distilled water, after which they were soaked in warm sterile distilled water for $24 \mathrm{~h}$, then germinated on plates containing pretreated sand $\left(121^{\circ} \mathrm{C}, 2 \mathrm{~h}\right)$. All germinated seeds were transferred to nursery containers when they reached $1 \mathrm{~cm}$ in length.

Glomus mosseae 0023 (GM) and G. intraradices 0042 (GI), obtained from the Beijing Academy of Agriculture and Forestry Science, were used as fungal inocula. The two inocula were propagated for 4 months in sterile potted soil containing cropped Trifolium repens L. in a controlled environmental chamber. Both inoculates contained substrate, root segments, hyphae and spores. The number of spores in mycorrhizal inoculum was 30.8/g (GM) and 114.6/g (GI), respectively. The root colonization rate was 76.73\% (GM) and 91.03\% (GI), respectively. Four inoculations were performed: GM, G. mosseae alone; GI, G. intraradices alone; GH (a code name), a mixture of 50\% G. mosseae and 50\% G. intraradices; and control, no AMF. Three seedlings were used per pot, with three replicates per treatment. On Day 40 , three similar-sized seedlings were transplanted to plastic pots $(30 \mathrm{~cm}$ deep with a $24-\mathrm{cm}$ diameter) containing $5 \mathrm{~kg}$ of sterilized soil. Before transplantation, $100 \mathrm{~g}$ of inoculum mixture and sterilized mycorrhizal inoculum were placed $5 \mathrm{~cm}$ below the surface of the substrate in each mycorrhizal treatment pot for fungal treatment. To ensure the same number of spores in each treatment, inocula were prepared to contain $100 \%$ (GM), $26.88 \%$ (GI) and $63.44 \%$ (GH, 50-g GM and 13.44-g GI) of the total weight. The control pots received the same amount of sterilized mycorrhizal inoculum. Morus alba L. seedlings were grown in a greenhouse from August to November in 2011 for 90 days. The experiment was conducted in a greenhouse at the Chinese Academy of Forestry with 12-h diurnal light/dark cycles; a temperature of 25 ${ }^{\circ} \mathrm{C}$ in the light cycle and $18{ }^{\circ} \mathrm{C}$ in the dark cycle; a 6.7-lumen output flux; and 70\% relative humidity. The containers were irrigated with distilled water to maintain the moisture level at field capacity, and to guarantee sufficient nutrient supply, seedlings were fed Hoagland nutrient solution every 3 weeks.

\subsection{Plant Measurements, Nutrient Analysis and Mycorrhizal Colonization}

The growth and physiological parameters of the plants were measured 90 days after the beginning of treatment. Plant height was measured using a steel ruler; the base diameter was measured using vernier calipers. After the seedlings were treated for 90 days, whole seedlings were removed from the pots. The shoots and roots were then dried at $105^{\circ} \mathrm{C}$ for $30 \mathrm{~min}$ and $80{ }^{\circ} \mathrm{C}$ for $24 \mathrm{~h}$, after which they were dried to a constant weight in an oven, and the total seedling biomass was calculated as the sum of the shoot and root dry weights. Mycorrhizal dependency (MD) was defined according to Gerdemann (1974) as "the degree to which a plant is dependent on the mycorrhizal condition to produce its maximum growth or yield at 
a given level of soil fertility [12]." In this study, MD = mycorrhizal plant dry weight/non-mycorrhizal plant dry weight $\times 100 \%$.

The AMF colonization rate was measured as described by Biermann (1981) [13], and the roots were stained and destained as described by Phillips and Hayman (1970) [14]. The roots were harvested and cut into segments of $1.5 \mathrm{~cm}$ for each treatment and then cleared with $10 \%(\mathrm{w} / \mathrm{v})$ potassium hydroxide $(\mathrm{KOH})$ and incubated at $90{ }^{\circ} \mathrm{C}$ for $15 \mathrm{~min}$. After removal of the $\mathrm{KOH}$, the roots were washed until the brown color disappeared. The clear roots were then soaked in $2 \%$ hydrochloric acid (w/v) for 5 min and washed under running tap water. The root segments were stained in $0.05 \%$ trypan blue prepared in lactophenol for $25 \mathrm{~min}$ (incubated in $90{ }^{\circ} \mathrm{C}$ water). The roots were then destained and stored in clean lactophenol. The stained root segments were observed under a microscope: 50 stained root segments of each pot were randomly selected, prepared as permanent slides and viewed under a stereomicroscope at $12 \times$ and $50 \times$. Colonization was measured as the proportion of the total number of root segments colonized by AMF (root segments with vesicles, arbuscules or hyphae were treated as AMF-colonized root segments). The AMF colonization rate $=$ infected root segments/total root segments $\times 100 \%$.

The plant inorganic nutrient content was examined by analyzing elements in the roots, shoots and leaves. The samples were oven-dried at $105^{\circ} \mathrm{C}$ for $30 \mathrm{~min}$ and then at $80{ }^{\circ} \mathrm{C}$ for $24 \mathrm{~h}$ until a constant weight was reached. Each sample $(0.2 \mathrm{~g})$ was collected by coning and quartering and added to a $100-\mathrm{mL}$ Kjeldahl flask containing $5 \mathrm{~mL}$ of concentrated sulfuric acid. The mixtures were gently shaken and then heated until they turned brown-black. After cooling, $5 \mathrm{~mL}$ of $30 \%(\mathrm{w} / \mathrm{v}) \mathrm{H}_{2} \mathrm{O}_{2}$ were added to the solution. The mixtures were then gently shaken and heated again for $20 \mathrm{~min}$. The last step was repeated until the liquid became clear, and the flasks were heated for $10 \mathrm{~min}$ until the $\mathrm{H}_{2} \mathrm{O}_{2}$ was eliminated. Distilled water was then added to each flask to a final volume of $100 \mathrm{~mL}$. Each solution was analyzed for N, P and K. The total nutrient content was determined using the Kjeldahl method [15]; P was determined using the Mo-Sb colorimetric method [16]; and total $\mathrm{K}$ was detected using ammonium acetate extraction-flame photometry [17].

\subsection{Chlorophyll Content and Root Activity}

Fresh tissue $(1.0 \mathrm{~g})$ was sampled from the second expanded leaf from the top of each plant. Chlorophyll was extracted with $90 \%$ acetone and measured using a UV/visible spectrophotometer at 663, 645 and $750 \mathrm{~nm}$ according to methods in Inskeep et al. (1985) [18]. The absorbance at $750 \mathrm{~nm}$ was subtracted from the absorbance at the other two wavelengths to correct for any turbidity in the extract prior to chlorophyll concentrations being calculated using the following formulas:

$$
\begin{aligned}
& \text { Chlorophyll A }(\mathrm{mg} / \mathrm{mL})=11.64 \times\left(\mathrm{A}_{663}\right)-2.16 \times\left(\mathrm{A}_{645}\right) \\
& \text { Chlorophyll B }(\mathrm{mg} / \mathrm{mL})=20.97 \times\left(\mathrm{A}_{645}\right)-3.94 \times\left(\mathrm{A}_{663}\right)
\end{aligned}
$$

where $\mathrm{A}_{663}$ and $\mathrm{A}_{645}$ represent the absorbance at 663 and $645 \mathrm{~nm}$, respectively.

As an important organ for absorption and synthesis, plant roots directly affect the growth of branches and leaves and play a role in supporting belowground plant components and in absorbing moisture and mineral nutrition from the soil; thus, they play a role in both plant growth and metabolism. In this experiment, root activity was determined using the 2,3,5-triphenyl tetrazolium chloride (TTC) method. According to Wu et al. (2013) [19], roots (0.5 g) were cut into $1-\mathrm{cm}$ segments, added to a test tube with 
$5 \mathrm{~mL}$ of $0.4 \%(\mathrm{~m} / \mathrm{v})$ TTC and $5 \mathrm{~mL}$ of $0.1 \mathrm{~mol} / \mathrm{L}$ phosphate buffer $\left(0.05 \mathrm{~mol} / \mathrm{L} \mathrm{Na} 2 \mathrm{HPO}_{4}\right.$ and $0.05 \mathrm{~mol} / \mathrm{L}$ $\mathrm{KH}_{2} \mathrm{PO}_{4}$ ) and incubated for $1 \mathrm{~h}$ at $37{ }^{\circ} \mathrm{C}$ in the dark. Subsequently, $2 \mathrm{~mL}$ of $2 \mathrm{~mol} / \mathrm{L} \mathrm{H}_{2} \mathrm{SO}_{4}$ were added to the test tube to terminate the reaction. Afterwards, the roots were removed from the test tube and dried with paper towels. The dry roots were ground with quartz sand and 3-4 $\mathrm{mL}$ of acetic ether in a mortar, to extract three phenyl methyl hydrazone (TTF). The extract was transferred to a test tube, the residue washed three times with acetic ether, and a constant volume of $10 \mathrm{~mL}$ was maintained using acetic ether. The absorbance of the extract at $485 \mathrm{~nm}$ was recorded. Root activity was expressed as: TTC reduction mass $(\mathrm{mg}) /$ root fresh mass $(\mathrm{g}) \times$ time $(\mathrm{h})$.

\subsection{Statistics}

The data were statistically analyzed by a one-way ANOVA with SPSS 19.0.

\section{Results}

\subsection{The AMF Colonization Rate}

Mulberry seedlings were colonized after all treatments involving inoculation with AMF (Figure 1). The non-inoculated samples showed no colonization. However, colonization rates between the three treatments showed significant differences $(p<0.05)$. The colonization rates were: $49.83 \%(\mathrm{GM}), 61.64 \%$ (GI) and 40.40\% (GH) (Figure 2). The AMF colonization rate showed the following pattern from high to low: $\mathrm{GI}>\mathrm{GM}>\mathrm{GH}$.
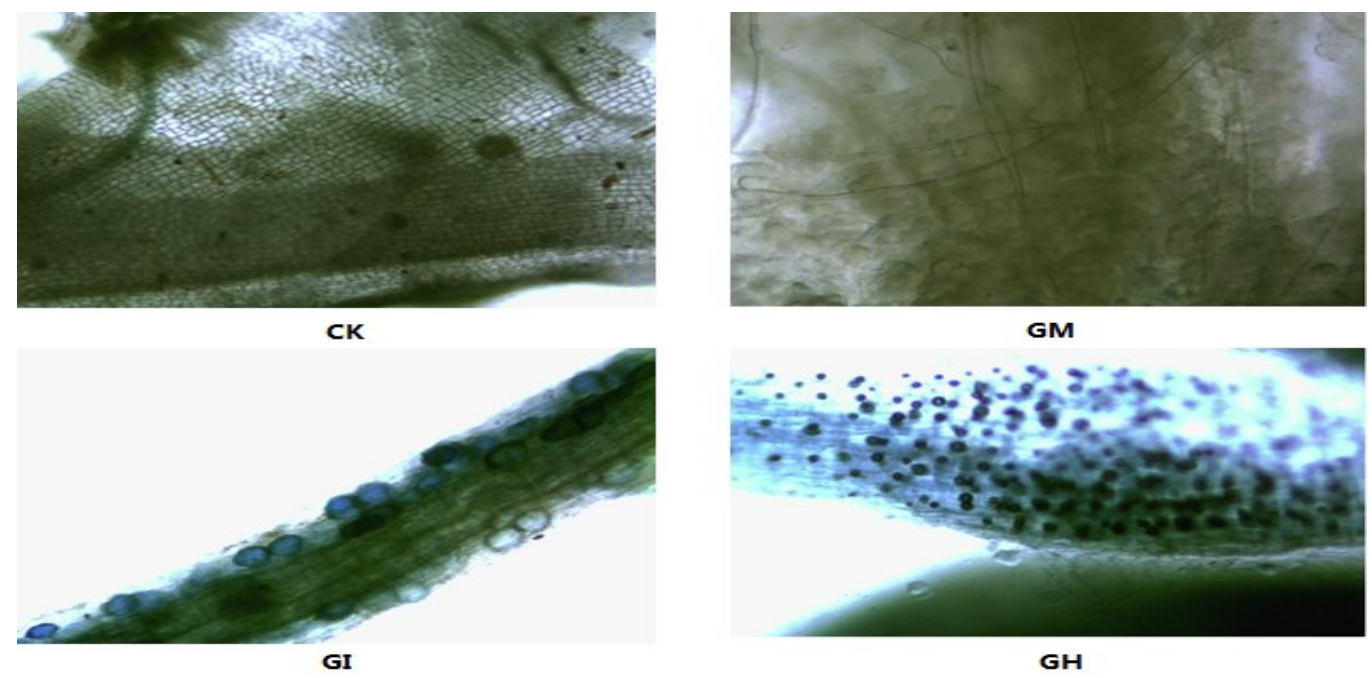

Figure 1. Arbuscular mycorrhizal fungal (AMF) colonization of mulberry seedling roots: Glomus mosseae (GM), Glomus intraradices (GI), a mixture of 50\% Glomus mosseae and $50 \%$ Glomus intraradices (GH) and Controls, without AMF (CK). 


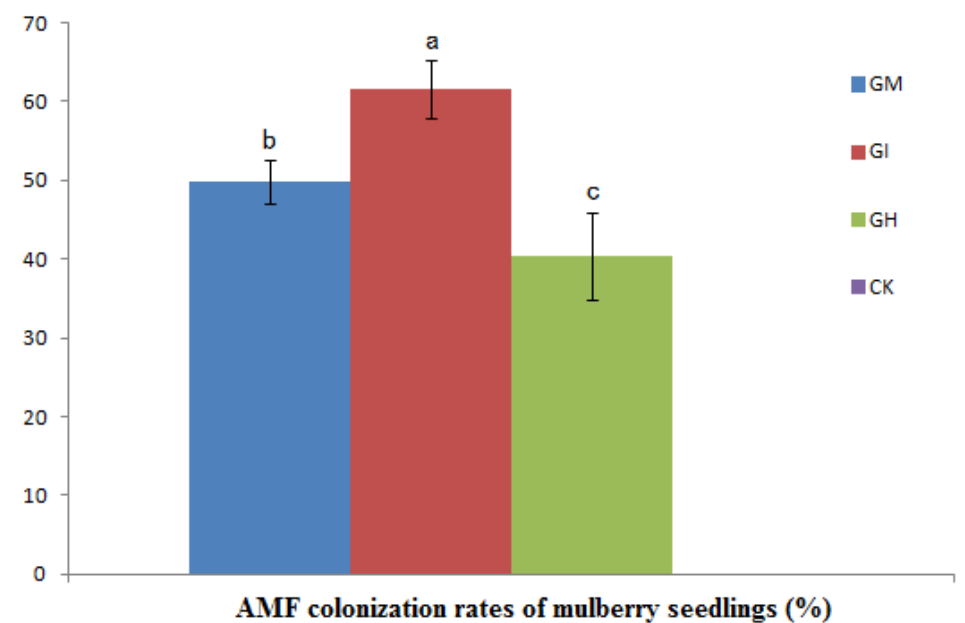

Figure 2. AMF colonization rates of mulberry seedlings: Glomus mosseae (GM), Glomus intraradices (GI), a mixture of Glomus mosseae and Glomus intraradices (GH) and Controls, without AMF (CK).

\subsection{Plant Growth, Biomass and Mycorrhizal Dependence}

Excluding the base diameter (Figure 3B), all growth parameters of the AMF colonized plants were significantly higher than in the control. The GI treatment had a significant effect on total biomass (Table 1), lateral root number (Figure 3D) and plant height (Figures 3A and 4). The GM treatment had the greatest influence on leaf number (Figure 3E) and root length (Figures $3 \mathrm{C}$ and 4 ).

Table 1. Effect on the biomass of mulberry seedlings grown in soil inoculated with: Glomus mosseae (GM), Glomus intraradices (GI), a mixture of Glomus mosseae and Glomus intraradices $(\mathrm{GH})$ and without AMF (CK).

\begin{tabular}{|c|c|c|c|c|c|c|}
\hline \multirow[b]{2}{*}{ Treatments } & \multicolumn{2}{|c|}{ Fresh Weight (g/pot) } & \multirow{2}{*}{$\begin{array}{c}\text { Total Fresh } \\
\text { Weight (g/pot) }\end{array}$} & \multicolumn{2}{|c|}{ Dry Weight (g/pot) } & \multirow{2}{*}{$\begin{array}{c}\text { Total Dry } \\
\text { Weight } \\
\text { (g/pot) }\end{array}$} \\
\hline & $\begin{array}{l}\text { Aboveground } \\
\text { Plant Parts }\end{array}$ & $\begin{array}{l}\text { Belowground } \\
\text { Plant Parts }\end{array}$ & & $\begin{array}{l}\text { Aboveground } \\
\text { Plant Parts }\end{array}$ & $\begin{array}{l}\text { Belowground } \\
\text { Plant Parts }\end{array}$ & \\
\hline GM & $76.10 \pm 5.33^{\mathrm{ab}}$ & $69.00 \pm 7.33^{\mathrm{ab}}$ & $145.10 \pm 12.66^{\mathrm{ab}}$ & $38.45 \pm 2.76^{\mathrm{ab}}$ & $34.43 \pm 1.95 \mathrm{ab}$ & $72.88 \pm 4.71^{\mathrm{ab}}$ \\
\hline GI & $96.91 \pm 8.52^{\mathrm{a}}$ & $78.42 \pm 8.46^{\mathrm{a}}$ & $175.33 \pm 16.98^{a}$ & $46.29 \pm 4.12^{\mathrm{a}}$ & $39.39 \pm 3.54^{\mathrm{a}}$ & $85.67 \pm 7.66^{\mathrm{a}}$ \\
\hline $\mathrm{GH}$ & $84.61 \pm 7.83^{a b}$ & $69.88 \pm 6.43^{\mathrm{ab}}$ & $154.49 \pm 14.26^{\mathrm{ab}}$ & $37.99 \pm 3.55^{\mathrm{ab}}$ & $37.39 \pm 2.87^{\mathrm{a}}$ & $75.38 \pm 6.42 \mathrm{ab}$ \\
\hline $\mathrm{CK}$ & $67.83 \pm 5.52^{b}$ & $60.28 \pm 6.65^{b}$ & $128.11 \pm 12.17^{b}$ & $31.74 \pm 3.43^{b}$ & $29.43 \pm 2.10^{\mathrm{b}}$ & $61.18 \pm 5.53^{b}$ \\
\hline
\end{tabular}

Note: Different letters denote significant differences $(p<0.05)$ between treatments according to Duncan's multiple range test. 

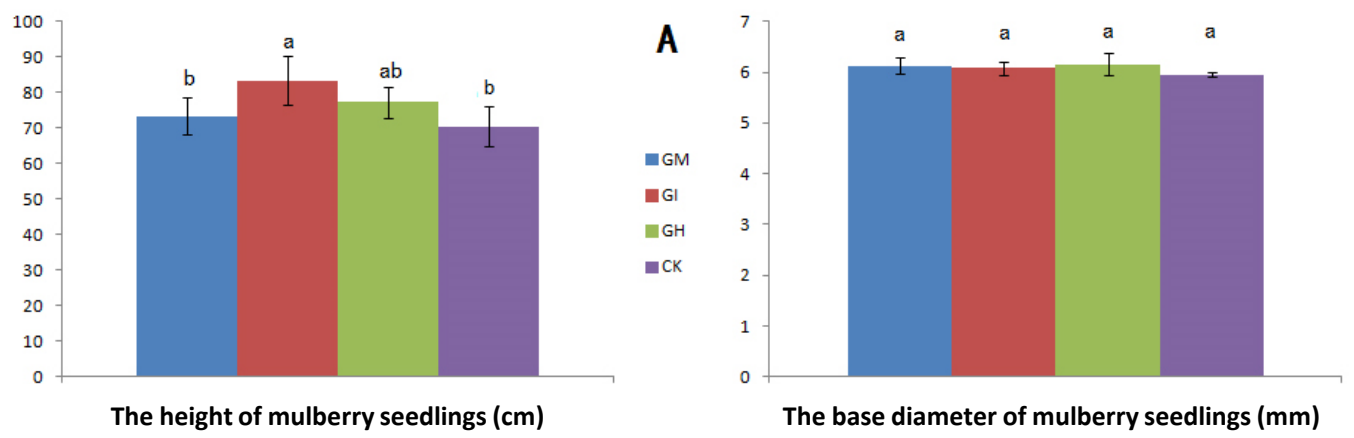

B

GM

GI

- $\mathrm{GH}$

- $\mathrm{CK}$

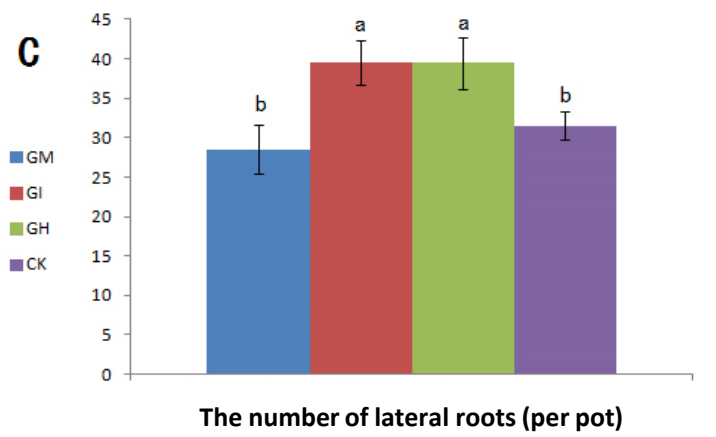

D

aM

E

EM

$\square \mathrm{GI}$

$\mathrm{GH}$

घCK

Figure 3. Effects of AMF inoculation on mulberry seedling growth: Glomus mosseae (GM), Glomus intraradices (GI), a mixture of Glomus mosseae and Glomus intraradices (GH) and without AMF (CK). (A) Plant height; (B) plant base diameter; (C) root length; (D) number of lateral roots; and $(\mathbf{E})$ number of leaves. Note: different letters denotesignificant differences $(p<0.05)$ between treatments according to Duncan's multiple range test.
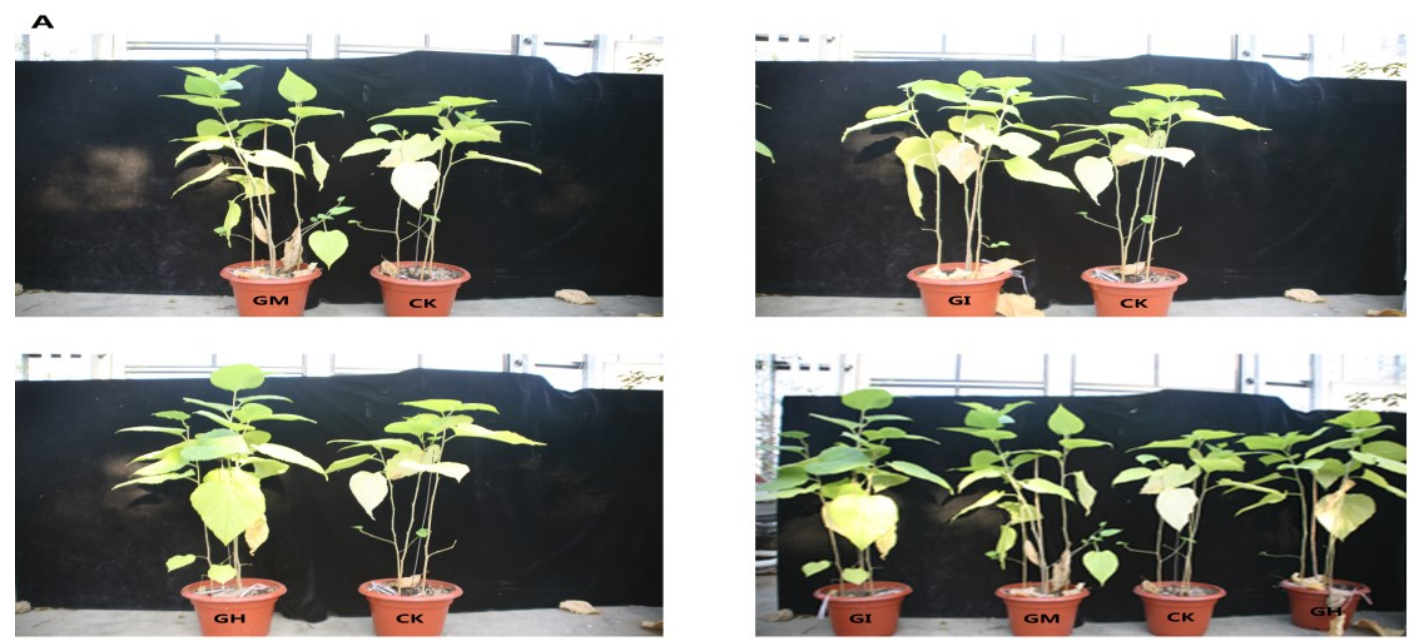

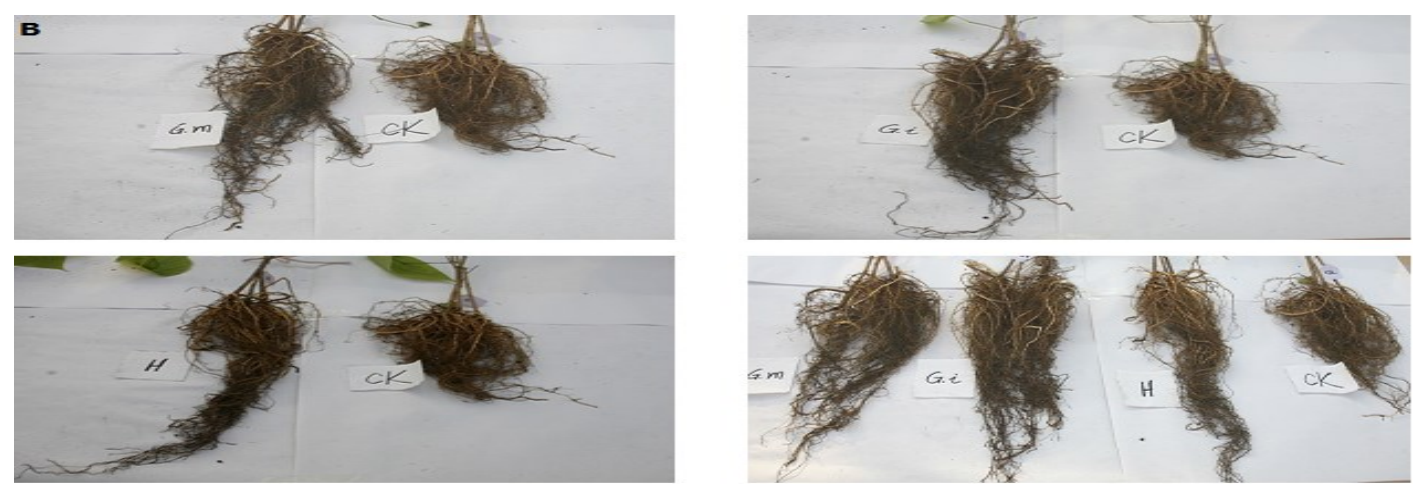

Figure 4. Growth of mulberry seedlings inoculated with: Glomus mosseae (GM), Glomus intraradices (GI), a mixture of Glomus mosseae and Glomus intraradices (GH) and Controls (CK): (A) aboveground and (B) belowground growth.

Based on Figures 3 and 4, the roots of the AMF-inoculated mulberry plants were significantly longer than the control roots. In the three inoculation treatments (GM, GI and GH), root length increased by $41.23 \%, 23.29 \%$ and $26.52 \%$, respectively, compared with controls roots (Figure 4).

The GI and GH treatments significantly increased the number of lateral roots in the mulberry seedlings by $33.33 \%$ compared to the controls; however, the GM treatment did not increase the number of lateral roots, and the treated plants showed a lower number of lateral roots than the controls (Figure 3D).

The number of leaves for the three inoculation treatments (GM, GI and GH) increased by $31.82 \%$, $27.27 \%$ and $22.73 \%$, respectively, compared with CK leaves; however, only the GM treatment reached a significant level (Figure 3E). The mycorrhizal dependence of the inoculated mulberry seedlings was highest (140\%) in the GI treatment, followed by the GH (123\%) and GM (119\%) treatments (Table 2).

Table 2. Mycorrhizal dependence (MD) of inoculated mulberry seedlings: Glomus mosseae (GM), Glomus intraradices (GI) and a mixture of Glomus mosseae and Glomus intraradices $(\mathrm{GH})$.

\begin{tabular}{cccc}
\hline Treatment & Dry Biomass (g/pot) & Dry Biomass of Control (g/pot) & MD (\%) \\
\hline GM & $72.88 \pm 4.71^{\mathrm{b}}$ & & $119.12 \pm 7.70^{\mathrm{b}}$ \\
GI & $85.67 \pm 7.66^{\mathrm{a}}$ & 61.18 & $140.03 \pm 12.52^{\mathrm{a}}$ \\
GH & $75.38 \pm 6.42^{\mathrm{b}}$ & & $123.21 \pm 10.49^{\mathrm{b}}$ \\
\hline
\end{tabular}

Note: Different letters denote significant differences $(p<0.05)$ between treatments according to Duncan's multiple range test.

\subsection{Chlorophyll Content}

The chlorophyll A content of the plant leaves in the three AMF treatment groups (GM, GI and GH) was increased by $13.44 \%, 51.01 \%$ and $44.97 \%$, respectively, compared to control leaves (Figure 5A). However, differences in chlorophyll A content were only significant for the GI and GH treatments (Figure 5A). The chlorophyll B content did not differ between any treatments (Figure 5B). 

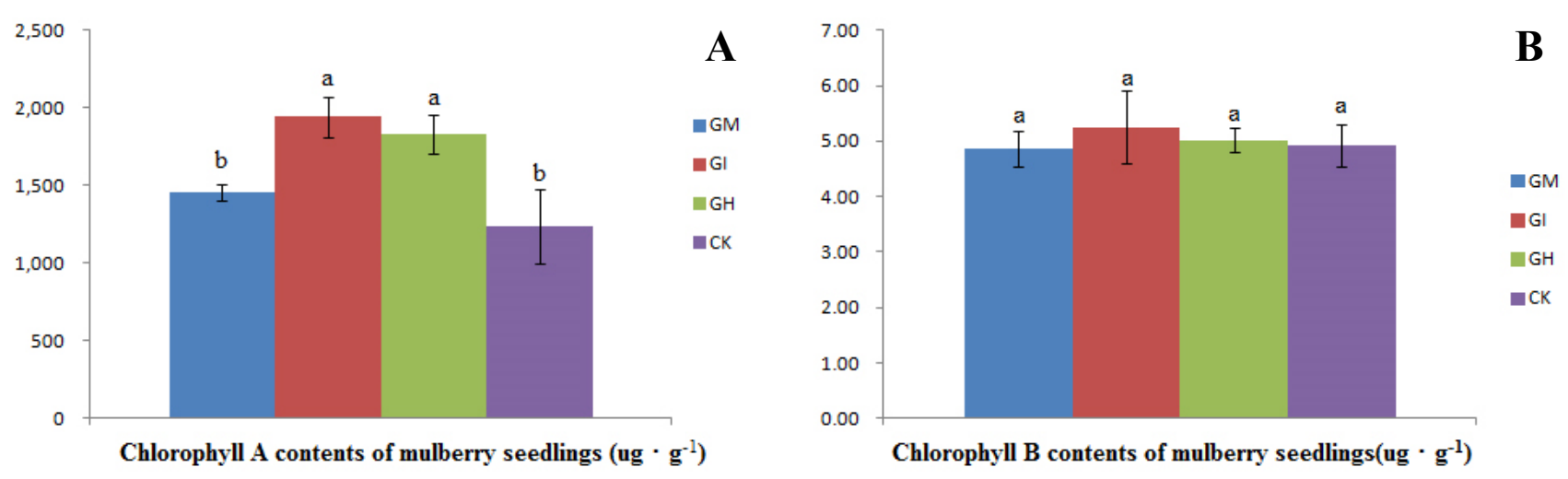

Figure 5. Effects of AMF inoculation on the chlorophyll A (A) and chlorophyll B (B) contents of mulberry seedlings: Glomus mosseae (GM), Glomus intraradices (GI), a mixture of Glomus mosseae and Glomus intraradices $(\mathrm{GH})$ and without AMF (CK). Note: different letters denote significant differences $(p<0.05)$ between treatments according to Duncan's multiple range test.

\subsection{The Influence on Root Activity}

The TTC deoxidizing ability of the GM, GI and GH plants increased by $19.02 \%, 58.59 \%$ and $20.27 \%$ compared to the controls, respectively, resulting in significantly higher levels, especially under GI treatment (Figure 6).

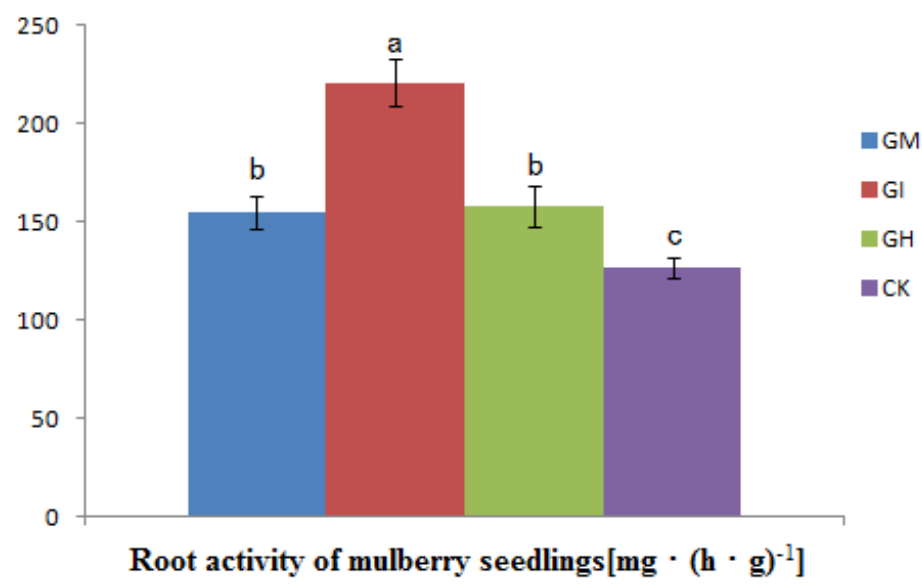

Figure 6. Effects of AMF inoculation on the root activity of mulberry seedlings: Glomus mosseae (GM), Glomus intraradices (GI), a mixture of Glomus mosseae and Glomus intraradices $(\mathrm{GH})$ and without AMF (CK). Note: different letters denote significant differences $(p<0.05)$ between treatments according to Duncan's multiple range test.

\subsection{Nutritional Content}

In our study, all three AMF-inoculated groups showed improved nutrient accumulation. The GI treatment resulted in the most efficient nutrient absorption (Table 3), with increases of $66.5 \%(\mathrm{~N}), 36.5 \%$ (P) and $48.6 \%(\mathrm{~K})$ in plants. Inoculation treatments significantly improved the plant nutrient content, excluding the $\mathrm{P}$ contents of the leaf. GI treatment increased the content of all three nutrient elements in 
the stems and roots most significantly, but did not improve the leaf $\mathrm{N}$ content. GH treatment significantly increased the leaf $\mathrm{N}$ content.

Although the three treatments did not significantly increase leaf $\mathrm{P}$ content, the total accumulation of P was $36.5 \%(\mathrm{GI}), 22.0 \%(\mathrm{GH})$ and $14.8 \%(\mathrm{GM})$ higher than that in the controls, respectively. All three treatment groups showed significantly increased root nutrient contents. The mixed treatment (GH) did not result in superior nutrient uptake compared with either the GM or GI treatments.

Table 3. Nutrient content (mg/pot) in leaves, stems and roots of mulberry seedlings: Glomus mosseae (GM), Glomus intraradices (GI), a mixture of Glomus mosseae and Glomus intraradices (GH) and without AMF (CK).

\begin{tabular}{|c|c|c|c|c|c|c|c|c|c|}
\hline \multirow{2}{*}{ Treatment } & \multicolumn{3}{|c|}{ Nitrogen } & \multicolumn{3}{|c|}{ Phosphorus } & \multicolumn{3}{|c|}{ Potassium } \\
\hline & Leaf & Stem & Root & Leaf & Stem & Root & Leaf & Stem & Root \\
\hline GM & $\begin{array}{c}183.1 \pm \\
20.6^{\mathrm{b}}\end{array}$ & $\begin{array}{c}218.4^{ \pm} \\
11.9^{\mathrm{b}}\end{array}$ & $\begin{array}{c}254.6 \pm \\
1.8^{\mathrm{ab}}\end{array}$ & $\begin{array}{c}18.5^{ \pm} \\
2.1^{\mathrm{a}}\end{array}$ & $\begin{array}{c}49.9 \pm \\
2.7^{\mathrm{ab}}\end{array}$ & $\begin{array}{c}63.8 \pm \\
3.2^{\mathrm{ab}}\end{array}$ & $\begin{array}{c}160.9 \pm \\
18.1^{\mathrm{b}}\end{array}$ & $\begin{array}{c}248.2^{ \pm} \\
13.5^{\mathrm{b}}\end{array}$ & $\begin{array}{c}346.2^{ \pm} \\
5.2^{\mathrm{a}}\end{array}$ \\
\hline GI & $\begin{array}{c}223.8 \pm \\
7.4^{\mathrm{ab}}\end{array}$ & $\begin{array}{c}328.4 \pm \\
28.3^{\mathrm{a}}\end{array}$ & $\begin{array}{c}354.0 \pm \\
91.1^{\mathrm{a}}\end{array}$ & $\begin{array}{c}25.1 \pm \\
0.8^{\mathrm{a}}\end{array}$ & $\begin{array}{c}59.2^{ \pm} \\
5.1^{\mathrm{a}} \\
\end{array}$ & $\begin{array}{c}72.9 \pm \\
9.0^{\mathrm{a}}\end{array}$ & $\begin{array}{c}244.9 \pm \\
8.1^{\mathrm{a}} \\
\end{array}$ & $\begin{array}{c}312.3^{ \pm} \\
26.9^{\mathrm{a}}\end{array}$ & $\begin{array}{c}359.2^{ \pm} \\
19.6^{\mathrm{a}}\end{array}$ \\
\hline $\mathrm{GH}$ & $\begin{array}{c}275.3 \pm \\
54.9^{a}\end{array}$ & $\begin{array}{c}220.0 \pm \\
20.2^{b}\end{array}$ & $\begin{array}{c}262.0 \pm \\
15.8^{\mathrm{ab}}\end{array}$ & $\begin{array}{c}24.5 \pm \\
4.9^{\mathrm{a}}\end{array}$ & $\begin{array}{c}47.1^{ \pm} \\
4.3^{\mathrm{b}}\end{array}$ & $\begin{array}{c}69.0 \pm \\
6.0^{\mathrm{a}}\end{array}$ & $\begin{array}{c}197.6 \pm \\
39.4^{\mathrm{ab}}\end{array}$ & $\begin{array}{c}245.8 \pm \\
22.6^{b}\end{array}$ & $\begin{array}{c}366.3 \pm \\
8.8 \\
\text { a }\end{array}$ \\
\hline $\mathrm{CK}$ & $\begin{array}{c}168.4 \pm \\
54.9^{\mathrm{b}}\end{array}$ & $\begin{array}{c}178.2 \pm \\
29.4^{\mathrm{b}}\end{array}$ & $\begin{array}{c}197.6 \pm \\
6.0^{\mathrm{b}}\end{array}$ & $\begin{array}{c}18.9 \pm \\
6.2^{\mathrm{a}}\end{array}$ & $\begin{array}{c}41.9^{ \pm} \\
6.9^{b}\end{array}$ & $\begin{array}{c}54.7 \pm \\
1.8^{\mathrm{b}}\end{array}$ & $\begin{array}{c}138.3 \pm \\
45.1^{\mathrm{b}}\end{array}$ & $\begin{array}{c}203.7^{ \pm} \\
33.6^{\mathrm{b}}\end{array}$ & $\begin{array}{c}274.6 \pm \\
27.7^{b}\end{array}$ \\
\hline
\end{tabular}

Note: Different letters denote significant differences $(p<0.05)$ between treatments according to Duncan's multiple range test.

\section{Discussion}

The characteristics of AMF and host plants play an important role in AMF colonization. In our study, the three treatments showed AMF colonization of the roots of mulberry seedlings after 90 days. However, the colonization rates for the three inoculation treatments differed. The colonization rate for the GI treatment was $61.64 \%$, which is significantly higher than for the GM $(49.83 \%)$ or GH (40.40\%) treatments. The colonization rate for the GI treatment was significantly higher than for the GM or GH treatments, which may be due to the different degree of host specificity in mulberry. Interestingly, the mixed inoculation $(\mathrm{GH})$ group showed lower colonization rates than the GM and GI groups, which were inoculated with a single species. Bennett et al. (2009) found that AMF species competed for root space and that the best competitor was the worst mutualist, while the worst competitor was the best mutualist [20]. In some cases, competition between two or more fungal species could result in the exclusion of an AMF species from host roots. The mechanism of competition during mycorrhiza formation has a physiological basis and may involve the carbohydrate supply of the host [21]. Hepper et al. (1988) suggested that the successful establishment of a mycorrhizal inoculate in the soil depends on the indigenous mycorrhizal species [22]. These studies indicate that a mixed inoculate may reduce the spore yield and create competition among various AMF species [22,23]. Thus, competition between different AMF should be taken into consideration if such species are used for seedling cultivation. 
Inoculation with AMF species, which has previously been applied to other plants, may be used to increase mulberry plant growth. Our results showed that mulberry plants inoculated with AMF had a higher aerial biomass and root biomass than non-mycorrhizal plants, which means the mycorrhizal plants had improved growth over the non-mycorrhizal plants. This is in agreement with many greenhouse studies on plants, such as tomatoes [24], oranges [25], cotton [26] and others [27].

It is known that AMF stimulate plant growth through a range of mechanisms that include improved nutrient acquisition [28], and AMF and non-AMF plants often display differences in the photosynthetic rate [29]. In our study, we found that the inorganic nutrient $(\mathrm{N}, \mathrm{P}, \mathrm{K})$ contents of AMF-colonized mulberry seedlings were higher than in non-AMF-colonized seedlings, which indicates that AMF colonization may improve nutrient absorption and accumulation, a phenomenon similar to that in other plants [30,31].

In our study, we found a significant increase in chlorophyll A content, which is possibly due to improved $\mathrm{N}$ and $\mathrm{K}$ uptake [32,33]. A change in chlorophyll has been found to correlate positively with photosynthetic capacity, and a screening of progeny for a high photosynthetic rate could be accomplished in a breeding program by measuring chlorophyll content [34,35]. However, Reynolds et al. (2005) demonstrated that AMF colonization could not enhance $\mathrm{N}$ acquisition, nor the growth of old-field perennials under low $\mathrm{N}$ conditions [36], indicating that the ability of AMF to promote the growth of host plants may be restricted by the availability of nutrients in the soil. In future studies, we will explore the performance of AMF-colonized seedlings under nutrient-limited conditions, to examine the possibility of mycorrhizal-induced growth depressions due to nutrient competition between host plants and fungi.

In our study, inoculation and colonization with G. mosseae and G. intraradices improved the growth and nutrient uptake of mulberry seedlings. These species are known to be beneficial for maize, Prunus cerasifera, olive trees and other plants, even under stressful conditions [37-40]. Compared to G. mosseae, G. intraradices had a higher root colonization capacity and increased plant growth, and the nutrient uptake of $M$. alba L. seedlings was also improved. This indicates that $G$. intraradices is a more efficient AMF species than G. mosseae when colonizing $M$. alba L. roots. However, the length of the roots and the number of the leaves of $M$. alba L. seedlings inoculated by G. mosseae were greater than those of $G$. intraradices-inoculated seedlings. This indicates that $G$. mosseae can also be used to improve seedling growth. Mixed treatment was not superior to inoculation of the plants with a single species. Our results are similar to those of Jansa et al. (2007), who showed that the effects of two or three AMF mixtures on plant growth and $\mathrm{P}$ uptake were mostly within the range of the effects exerted by the respective single species [41]. In their study, Jansa et al. also found that when G. mosseae was included in the mixture, the root community became dominated by this species, indicating that a dominant AMF species may strongly influence the composition of the AMF community in roots and, hence, influence the symbiotic performance of plants colonized by mixtures.

\section{Conclusions}

Both G. mosseae and G. intraradices improved the growth and nutrient uptake of mulberry seedlings, and simultaneous root colonization by two or more AMF may not be superior to the infection of plants with a single species. Our study provides a foundation for the application of $G$. mosseae and $G$. 
intraradices in mulberry cultivation. However, many other factors should be taken into account, including the performance of inoculated seedlings under field conditions. Experimental conditions, where the plants are inoculated with a limited number of AMF species and receive adequate nutrition, are not representative of field conditions in which multiple AMF species can be present in a single root system or in combination with nutrient or environmental stress.

\section{Acknowledgments}

The authors appreciate the financial support from the National Science and Technology Support Program (No. 2012BAC09B03); Beijing Bureau of Landscaping and Forestry Science and Technology Projects (No.2014-6); Beijing Municipal Science and Technology Commission Program (No. 111100066111001).

\section{Author Contributions}

Jinxing Zhou, Yun Li Conceived and designed the experiments; Nan Lu, Xia Zhou, Ming Cui, Meng $\mathrm{Yu}$, Yongsheng Qin performed the experiments; Nan Lu, Xia Zhou, Ming Cui wrote the paper together.

\section{Conflicts of Interest}

The authors declare no conflicts of interest.

\section{References}

1. Smith, S.E.; Read, D.J. Mycorrhizal Symbiosis; Academic Press: London, UK, 1996.

2. Gianinazzi, S.; Gollotte, A.; Binet, M.; van Tuinen, D.; Redecker, D.; Wipf, D. Agroecology: The key role of arbuscular mycorrhizas in ecosystem services. Mycorrhiza 2010, 20, 519-530.

3. Smith, S.E.; Smith, F.A. Roles of Arbuscular Mycorrhizas in Plant Nutrition and Growth: New Paradigms from Cellular to Ecosystem Scales. Ann. Rev. Plant Biol. 2011, 62, 227-250.

4. Jones, M.D.; Smith, S.E. Exploring functional definitions of mycorrhizas: Are mycorrhizas always mutualisms? Can. J. Bot. 2004, 82, 1089-1110.

5. Smith, F.A.; Smith, S.E. Mutualism and parasitism: Diversity in function and structure in the "arbuscular" (VA) mycorrhizal symbiosis. Adv. Bot. Res. 1996, 22, 1-43.

6. Van der Heijden, M.G.; Klironomos, J.N.; Ursic, M.; Moutoglis, P.; Streitwolf-Engel, R.; Boller, T.; Wiemken, A.; Sanders, I.R. Mycorrhizal fungal diversity determines plant biodiversity, ecosystem variability and productivity. Nature 1998, 396, 69-72.

7. Maherali, H.; Klironomos, J.N. Influence of Phylogeny on Fungal Community Assembly and Ecosystem Functioning. Science 2007, 316, 1746-1748.

8. Chang, Y.; Huang, K.; Huang, A.; Ho, Y.; Wang, C. Hibiscus anthocyanins-rich extract inhibited LDL oxidation and oxLDL-mediated macrophages apoptosis. Food Chem. Toxicol. 2006, 44, 1015-1023.

9. Butt, M.S.; Nazir, A.; Sultan, M.T.; Schroën, K. Morus alba L. Nature's functional tonic. Trends Food Sci. Technol. 2008, 19, 505-512. 
10. Katiyar, R.S.; Das, P.K.; Choudhury, P.C.; Ghosh, A.; Singh, G.B.; Datta, R.K. Response of irrigated mulberry (Morus alba L.) to VA-mycorrhizal inoculation under graded doses of phosphorus. Plant Soil. 1995, 170, 331-337.

11. Mamatha, G.; Bagyaraj, D.; Jaganath, S. Inoculation of field-established mulberry and papaya with arbuscular mycorrhizal fungi and a mycorrhiza helper bacterium. Mycorrhiza 2002, 12, 313-316.

12. Gerdemann, J.W.; Trappe, J.M. Endogonaceae in the Pacific Northwest. Mycologia Mem 1974, 5, $1-76$.

13. Biermann, B.; Linderman, R.G. Quantifying vesicular-Arbuscular mycorrhizae: A proposed method towards standardization. New Phytol. 1981, 87, 63-67.

14. Phillips, J.M.; Hayman, D.S. Improved procedures for clearing roots and staining parasitic and vesicular-arbuscular mycorrhizal fungi for rapid assessment of infection. Trans. Br. Mycol. Soc. 1970, 55, 118-158.

15. Bradstreet, R.B. The Kjeldahl Method for Organic Nitrogen; Academic Press Inc: New York, NY, USA, 1965.

16. Lu, R.K. Soil Analytical Methods of Agronomic Chemica; China Agricultural Science and Technology Press: Beijing, China, 2000.

17. Page, A.L. Methods of soil analysis. Part 2. In Chemical and Microbiological Properties; American Society of Agronomy, Soil Science Society of America: Madison, WI, USA, 1982.

18. Inskeep, W.P.; Bloom, P.R. Extinction coefficients of chlorophyll a and b in $N, N$-dimethylformamide and $80 \%$ acetone. Plant Physiol. 1985, 77, 483-485.

19. Wu, H.X.; Ma, Y.Z.; Xiao, J.P.; Zhang, Z.H.; Shi, Z.H. Photosynthesis and root characteristics of rice (Oryza sativa L.) in floating culture. Photosynthetica 2013, 51, 231-237.

20. Bennett, A.E.; Bever, J.D. Trade-offs between arbuscular mycorrhizal fungal competitive ability and host growth promotion in Plantago lanceolata. Oecologia 2009, 160, 807-816.

21. Pearson, J.N.; Abbott, L.K.; Jasper, D.A. Phosphorus, soluble carbohydrates and the competition between two arbuscular mycorrhizal fungi colonizing subterranean clover. New Phytol. 1994, 127, 101-106.

22. Hepper, C.M.; Azcon-Aguilar, C.; Rosendahl, S.; Sen, R. Competition Between Three Species of Glomus Used as Spatially Separated Introduced and Indigenous Mycorrhizal Inocula for Leek (Allium porrum L.). New Phytol. 1988, 110, 207-215.

23. Pearson, J.N.; Abbott, L.K.; Jasper, D.A. Mediation of Competition between Two Colonizing VA Mycorrhizal Fungi by the Host Plant. New Phytol. 1993, 123, 93-98.

24. Abdel Latef, A.A.H.; Chaoxing, H. Effect of arbuscular mycorrhizal fungi on growth, mineral nutrition, antioxidant enzymes activity and fruit yield of tomato grown under salinity stress. Sci. Hortic. 2011, 127, 228-233.

25. Wu, Q.S.; Xia, R.X. Effects of arbuscular mycorrhizal fungi on plant growth and osmotic adjustment matter content of trifoliate orange seedling under water stress. J. Plant Physiol. Mol. Biol. 2004, 30, 583-588.

26. Smith, G.S.; Roncadori, R.W. Responses of three vesicular-arbuscular mycorrhizal fungi at four soil temperatures and their effects on cotton growth. New Phytol. 1986, 104, 89-95. 
27. Shrestha, Y.H.; Ishii, T.; Kadoya, K. Effect of vesicular-arbuscular mycorrhizal fungi on the growth, photosynthesis, transpiration and the distribution of photosynthates of bearing satsuma mandarin (Citrus reticulata) trees. J. Jpn. Soc. Hortic. Sci. 1995, 64, 517-525.

28. Artursson, V.; Finlay, R.D.; Jansson, J.K. Interactions between arbuscular mycorrhizal fungi and bacteria and their potential for stimulating plant growth. Environ. Microbiol. 2006, 8, 1-10.

29. Sheng, M.; Tang, M.; Chen, H.; Yang, B.; Zhang, F.; Huang, Y. Influence of arbuscular mycorrhizae on photosynthesis and water status of maize plants under salt stress. Mycorrhiza 2008, 18, 287-296.

30. Al-Karaki, G.N. Growth of mycorrhizal tomato and mineral acquisition under salt stress. Mycorrhiza $2000,10,51-54$.

31. Jia, Y.; Gray, V.M.; Straker, C.J. The influence of Rhizobium and arbuscular mycorrhizal fungi on nitrogen and phosphorus accumulation by Vicia faba. Ann. Bot. 2004, 94, 251-258.

32. Menéndez, M.J.; Herrera-Silveira, J.; Comín, F.A. Effect of nitrogen and phosphorus supply on growth, chlorophyll content and tissue composition of the macroalga Chaetomorpha linum (O.F. Müll.) Kütz in a Mediterranean coastal lagoon. Sci. Mar. 2002, 66, 355-364.

33. Zhao, D.; Oosterhuis, D.M.; Bednarz, C.W. Influence of potassium deficiency on photosynthesis, chlorophyll content, and chloroplast ultrastructure of cotton plants. Photosynthetica 2001, 39, 103-109.

34. Buttery, B.R.; Buzzell, R.I. The relationship between chlorophyll content and rate of photosynthesis in soybeans. Can. J. Plant Sci. 1977, 57, 1-5.

35. Murchie, E.H.; Horton, P. Acclimation of photosynthesis to irradiance and spectral quality in British plant species: Chlorophyll content, photosynthetic capacity and habitat preference. Plant Cell Environ. 1997, 20, 438-448.

36. Reynolds, H.L.; Hartley, A.E.; Vogelsang, K.M.; Bever, J.D.; Schultz, P.A. Arbuscular mycorrhizal fungi do not enhance nitrogen acquisition and growth of old-field perennials under low nitrogen supply in glasshouse culture. New Phytol. 2005, 167, 869-880.

37. Eom, A.H.; Hartnett, D.C.; Wilson, G.W.T. Host plant species effects on arbuscular mycorrhizal fungal communities in tallgrass prairie. Oecologia 2000, 122, 435-444.

38. Estaun, V.; Camprubi, A.; Calvet, C.; Pinochet, J. Nursery and Field Response of Olive Trees Inoculated with Two Arbuscular Mycorrhizal Fungi, Glomus intraradices and Glomus mosseae. J. Am. Soc. Hortic. Sci. 2003, 128, 767.

39. Wu, S.C.; Cao, Z.H.; Li, Z.G.; Cheung, K.C.; Wong, M.H. Effects of biofertilizer containing N-fixer, $\mathrm{P}$ and $\mathrm{K}$ solubilizers and AM fungi on maize growth: A greenhouse trial. Geoderma 2005, 125, $155-166$.

40. Berta, G.; Gianinazzi-Pearson, V.; Gianinazzi, S. Arbuscular mycorrhizal induced changes to plant growth and root system morphology in Prunus cerasifera. Tree Physiol. 1995, 15, 281-293.

41. Jansa, J.; Smith, F.A.; Smith, S.E. Are there benefits of simultaneous root colonization by different arbuscular mycorrhizal fungi? New Phytol. 2008, 177, 779-789.

(C) 2015 by the authors; licensee MDPI, Basel, Switzerland. This article is an open access article distributed under the terms and conditions of the Creative Commons Attribution license (http://creativecommons.org/licenses/by/4.0/). 